\title{
A PSICOLOGIA DO ESPORTE NA FORMAÇÃO DE TÉCNICOS DESPORTIVOS
}

\author{
Isabel Dias \\ Instituto Politécnico de Leiria, Leiria, Portugal
}

\section{Resumo}

Este artigo procura dar a conhecer a metodologia de ensino/aprendizagem utilizada na unidade curricular de Psicologia do Esporte do 2. ${ }^{\circ}$ ano do curso de formação inicial de Esporte e Bem-Estar (Instituto Politécnico de Leiria - Escola Superior de Educação e Ciências Sociais) no ano letivo 2010/2011. Adotando-se uma metodologia ativa, incentivou-se a avaliação contínua focalizada na participação nas sessões, na avaliação individual e na realização de um trabalho de grupo. De um universo de 82 estudantes, 43 optaram pela avaliação contínua, tendo sido realizados 14 trabalhos. Neste contexto, propomo-nos partilhar os dados dos trabalhos de grupo de índole investigativo e o percurso formativo dos estudantes na sua elaboração.

Palavras-chave: Educação. Psicologia. Competências.

\section{Introdução}

A mudanças introduzidas no Ensino Superior com o processo de no/aprendizagem neste nível de ensino.

O desafio actual do Ensino Superior será promover o espírito crítico dos seus agentes educativos, facilitando processos de adaptação a um mundo em constante mutação, globalizante e globalizado. Como defende Garcia (2001, p. 37):

"Os saberes universitários têm que provocar no aluno a consciência da dúvida, a consciência heurística, a consciência de que a verdade pura ou abstrata é algo que não existe, mas que é realizada a todo o momento (...) privilegiando mais a formação/educação em detrimento da quantidade de informação, sem 
contudo abdicar da transmissão de pontos de referência, essenciais para que se possa estabelecer qualquer tipo de diálogo (...) criação de know-how intelectual que possibilitará um verdadeiro diálogo (...)".

Com a implementação do processo de Bolonha, Universidades e Institutos Politécnicos (re)descobriram-se enquanto facilitadores do inconformismo intelectual, portadores de conhecimento reflexivo, enquanto contextos nos quais se reflete e se incorpora o que se reflete. (Re)inventaram-se enquanto espaços de flexibilidade, de intervenção educativa na formação de técnicos/professores que se deseja que encarem o esporte/exercício físico/atividade física não como uma técnica, mas como uma cultura de sentido (PROENÇA, 1999).

É neste quadro de transformação social que entendemos que é necessário refletir sobre o que se faz em contexto de formação, como se faz e porque se faz. Atualmente, ensinar (jovens) adultos em contexto de Ensino Superior é:

(...) a organização intencional das situações nas quais a aprendizagem apropriada ocorrerá. (...) Nesse sentido, nós, os professores, organizamos coreografias que "postas em cena" orientam o processo de aprendizagem dos nossos estudantes. Essas situações podem ser reais e estar em espaços concretos (...) ou podem ser virtuais (...), mas em todo o caso, têm o mesmo papel: definem, concretizam e possibilitam oportunidades de aprendizagem" (BERAZA, 2006, p. 23).

Foi nesta perspectiva de oportunidade de aprendizagem que organizamos a unidade curricular de Psicologia do Esporte que integra o plano de estudos do curso de formação inicial de Esporte e Bem-Estar (Instituto Politécnico de Leiria - Escola Superior de Educação e Ciências Sociais), $2 .^{\circ}$ ano $/ 3 .^{\circ}$ semestre, a decorrer pela primeira vez no ano letivo 2010/2011. Conforme se pode ler no programa desta unidade curricular aprovado em Conselho Técnico-Científico (ESECS) no dia 07 de Outubro de 2010, p. 1:

(...) Pretende-se, neste espaço de aprendizagem, refletir com os estudantes sobre a pertinência desta área específica do saber para a sua futura prática profissional (...) De forma contextualiza- 
da, organizada e sistematizada, num clima de aceitação, colaboração, partilha e liberdade, os estudantes terão a possibilidade de discutir e refletir sobre fenômenos complexos que normalmente ocorrem em contexto desportivo e de atividade física seja no âmbito do exercício e lazer, formação desportiva ou alta competição (...)

No sentido de promover o desenvolvimento e aprendizagem dos estudantes, propõe-se a discussão das seguintes temáticas: (1) Psicologia do Esporte e do Exercício: conceito(s) e percurso(s); (2) efeitos e benefícios psicológicos do exercício e da atividade física; (3) motivação para a prática e competição desportiva; (4) liderança e comportamentos do treinador no esporte; (5) promoção de competências de vida através do esporte e da atividade física.

Considerando o estabelecido no Regulamento Geral da Formação Graduada e Pós-Graduada no Instituto Politécnico de Leiria (2008), a avaliação contínua resultou da realização de 2 testes de carácter individual (peso de $30 \%$ na classificação final); um trabalho em grupo (preferencialmente) de 3 elementos (peso 30\% na classificação final) e participação e desempenho dos estudantes nas aulas (peso de 10\% na classificação final).

Procurando dar resposta à componente de avaliação em grupo, os estudantes foram desafiados a conhecer o significado de competências de vida, a identificar competências de vida desenvolvidas em contexto desportivo e a refletir sobre a relação entre participação desportiva e desenvolvimento de competências de vida, escolhendo uma de duas hipóteses: trabalho de revisão da literatura (proposta A) ou ensaio investigativo (proposta $\mathrm{B}$ ). Para a concretização da proposta $\mathrm{B}$, os estudantes, em grupo, construíram e (re)construíram um roteiro de entrevista, selecionaram e contactaram os agentes desportivos a entrevistar, realizaram a entrevista pensada, a transcreveram e procuraram analisar e discutir os dados recolhidos, em uma perspectiva de investigação qualitativa de aspecto interpretativo.

Aspirava-se que os estudantes pudessem entender as representações dos entrevistados acerca das suas funções e atividades desportivas (GOMES, 2007) e refletissem sobre as competências de vida ${ }^{1}$

1-Definimos competências de vida como aquelas que permitem ao indivíduo ter sucesso no meio ambiente em que vive, seja na escola, em casa ou na vizinhança (DANISH, 1997; GOULD \& CARSON, 2008). Danish (1993, 1995) e Gould, 
desenvolvidas em contexto desportivo.

Ambicionava-se que os estudantes pudessem aprender sobre metodologia da investigação e sobre o desenvolvimento de competências de vida em contexto desportivo (temática 5). Neste sentido, foram facultados vários textos aos estudantes que visavam orientar o trabalho a desenvolver (CRUZ, 1996; CRUZ, GOMES \& DIAS, 1999; FRASES-THOMAS, COTÉ \& DEAKIN, 2005; GOMES, RAMALHO \& DIAS, 2010; SAMUELS, 2002; GOMES, 2007 e GOMES \& CRUZ, 2007). Procurou-se que os estudantes desenvolvessem uma aprendizagem situada e incorporada, na qual o saber fosse compreendido como um produto da atividade, do contexto e da cultura em que é desenvolvido e utilizado (PINHEIRO, 2005).

O trabalho, em anexo, deveria, ainda, incluir uma reflexão individual do processo de construção deste trabalho acadêmico e atas das reuniões de grupo realizadas. Foi acordado em conjunto um modelo de ata e sugerida a definição de papéis entre os diferentes elementos do grupo: secretário, facilitador, coordenador, em uma lógica de escola aprendente (ALARCÃO, 2009) na qual “(...) a natureza comunicativa entre os intervenientes (...) será a componente de maior investimento futuro" (FIGUEIREDO, 1997, p. 113).

Neste artigo, propomo-nos partilhar os dados dos trabalhos em grupo de índole investigativo e o percurso formativo dos estudantes na sua elaboração. Valorizando a pedagogia como campo de ensino/aprendizagem, de investigação e de desenvolvimento profissional, o ensaio investigativo procurou que os estudantes se apropriassem criticamente do conhecimento, valorizando práticas de colaboração, negociação e auto/co-regulação.

\section{Metodologia}

Investigar práticas de ensino/aprendizagem supõe a adoção de um paradigma naturalista com recurso preferencial a métodos qualitativos de recolha e análise de informação. Adotou-se o estudo de caso educacional como uma estratégia para desenvolver teoria educacional que promova a prática educativa (VIEIRA, 2005).

Chung, Smith, \& White (2006) defendem que estas competências compreendem as características pessoais do indivíduo, o controlo emocional, a auto-estima, o trabalho ético, etc.

Pensar a Prática, Goiânia, v. 15, n. 3, p. 551-820, jul./set. 2012 
O estudo foi conduzido retrospectivamente, depois da prática educativa do investigador/docente. Como defende Bulmer (1982, p. 255):

(...) o'observador' estava completamente imerso no contexto que estava estudando, mas não tinha ainda desenvolvido um interesse de pesquisa no mesmo. Nenhuma decepção dos estudados foi envolvida, nenhuma quebra de consentimento informado ocorreu, desde que nenhum estudo científico estava em vista na época em que o estudo foi conduzido ${ }^{2}$.

Pela focalização em grupos e contextos pedagógicos singulares, assume-se que o conhecimento produzido é situado e idiossincrático.

Assim, de um universo de 82 estudantes inscritos na unidade curricular de Psicologia do Esporte do 2. ${ }^{\circ}$ ano do curso (diurno e noturno) de formação inicial de Esporte e Bem-Estar (IPL-ESECS), no ano letivo 2010/2011, 43 optaram pela avaliação contínua, tendo sido realizados 14 trabalhos de grupo, 6 de revisão de literatura (17 estudantes) e 8 de índole investigativa ( 26 estudantes).

Este estudo centra a sua atenção nos 8 trabalhos de índole investigativa realizados pelos estudantes e estudados pelo docente/investigador. Os dados foram organizados em quadros com informações distintas: título do trabalho e agentes desportivos envolvidos, modalidades desportivas, blocos temáticos das entrevistas realizadas, roteiro de entrevista e indicadores de competências de vida.

Outro instrumento utilizado foi o registo de avaliação formativa facultada aos estudantes no final do semestre (janeiro 2011) e o registo das conquistas/dificuldades dos estudantes no processo de construção do trabalho em grupo de índole investigativo.

O processo de concretização deste estudo passou pela análise crítica da metodologia de ensino/aprendizagem utilizada na unidade curricular de Psicologia do Esporte (ano letivo 2010/2011) e pela seleção dos trabalhos a examinar. Fez-se uma leitura e análise dos roteiros de entrevista elaborados pelos estudantes e das transcrições das entrevistas. Escolheram-se os dados relativos aos agentes desportivos envolvi-

2- Do inglês "(...) the "observer" was completely immersed in the setting which he or she was studying, but had not yet developed a research interest in it. No deception of those studied was involved, no breach of informed consent occurred, since no scientific study was in view at the time the study was carried out".

Pensar a Prática, Goiânia, v. 15, n. 3, p. 551-820, jul./set. 2012 
dos, às modalidades desportivas em estudo, aos blocos temáticos das entrevistas realizadas, ao roteiro de entrevista e aos indicadores de competências de vida advindas das entrevistas.

Identificaram-se referentes relativos ao processo de construção do trabalho de grupo (avaliação formativa final e conquistas/dificuldades dos estudantes) e refletiu-se sobre o desempenho acadêmico dos estudantes nesta dimensão avaliativa.

Os dados qualitativos levantados foram associados à contagem de forma a encontrar um raciocínio que permitisse tirar conclusões plausíveis.

\section{Resultados}

Em seguida apresentam-se os dados advindos do trabalho acadêmico final.

\begin{tabular}{|c|c|}
\hline Título do Trabalho & Entrevistados \\
\hline $\begin{array}{l}\text { T1: "Treinadores, líderes e seres sociais: as } \\
\text { suas competências de vida" }\end{array}$ & $\begin{array}{l}\text { Treinadores de futebol } \\
\text { 1. Homem, } 36 \text { anos (ensaio) } \\
\text { 2. Homem, } 45 \text { anos } \\
\text { 3. } \text { Homem, } 43 \text { anos } \\
\end{array}$ \\
\hline $\begin{array}{l}\text { T2: "Promoção de competências de vida } \\
\text { com a prática desportiva" }\end{array}$ & $\begin{array}{l}\text { Jogadores de futebol (Divisão de } \\
\text { Honra): } \\
\text { 1. Homem, } 22 \text { anos } \\
\text { 2. Homem, } 28 \text { anos } \\
\end{array}$ \\
\hline T3: "Motivação em alta competição" & $\begin{array}{l}\text { Jogadores de futebol (1. }{ }^{\mathrm{a}} \text { Divisão) } \\
\text { 1. Homem, } 20 \text { anos } \\
\text { 2. Homem, } 19 \text { anos }\end{array}$ \\
\hline $\begin{array}{l}\text { T4: "Qual a relação entre motivação na alta } \\
\text { competição e competências de vida?" }\end{array}$ & $\begin{array}{l}\text { Treinador e jogadores de Badmington } \\
\text { 1. Homem, } 19 \text { anos (ensaio) } \\
\text { 2. Mulher, } 30 \text { anos } \\
\text { 3. Homem, } 37 \text { anos } \\
\end{array}$ \\
\hline T5: "Entrevistas em atletismo" & $\begin{array}{l}\text { Atletismo } \\
\text { 1. Mulher, } 33 \text { anos (Cross Country) } \\
\text { 2. Homem, } 21 \text { anos (Salto com } \\
\text { vara) }\end{array}$ \\
\hline $\begin{array}{l}\text { T6: "Qual o estilo de liderança que facilita o } \\
\text { desenvolvimento de competências de vida } \\
\text { em contexto de futsal?" }\end{array}$ & 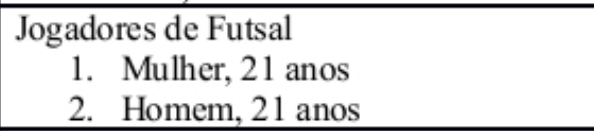 \\
\hline $\begin{array}{l}\text { T7: "Fatores motivacionais subjacentes à } \\
\text { prática desportiva de badmington" }\end{array}$ & $\begin{array}{l}\text { Jogadores de Badmington: } \\
\text { 1. Mulher, } 26 \text { anos } \\
\text { 2. Homem, } 20 \text { anos } \\
\end{array}$ \\
\hline $\begin{array}{l}\text { T8: "Diferenças de liderança em contextos } \\
\text { diferentes" }\end{array}$ & $\begin{array}{l}\text { Treinadores } \\
\text { 1. Homem, } 44 \text { anos (Handebol) } \\
\text { 2. Homem, } 37 \text { anos (Taekwondo) }\end{array}$ \\
\hline
\end{tabular}

Quadro 1: Trabalhos dos estudantes e agentes desportivos entrevistados 
No seu conjunto, os 26 estudantes que optaram pela realização deste trabalho, entrevistaram 18 agentes desportivos (6 treinadores e 12 atletas) de 6 modalidades distintas (futebol, badmington, atletismo, futsal, handebol e taekwondo), 14 sujeitos do sexo masculino e 4 do sexo feminino. Destas 18 entrevistas, duas foram entrevistas denominadas de ensaio/avaliação do roteiro.

Pelos títulos dos trabalhos, podemos afirmar que estes estudantes se centraram na questão da liderança (T1, T6, T8), da motivação (T3, T4 e T7) e das competências de vida em geral (T2). O título do trabalho 5 não permite aferir o conteúdo do mesmo.

Os roteiros de entrevista organizaram-se em torno de diferentes blocos temáticos (Quadro 2):

\begin{tabular}{|c|c|c|}
\hline Trabalho & N. ${ }^{\circ}$ e nome dos blocos temáticos & N. ${ }^{0}$ questões \\
\hline 1 & $\begin{array}{l}\text { 1. Apresentação } \\
\text { 2. Situação profissional e percurso desportivo } \\
\text { 3. Liderança } \\
\text { 4. Responsabilidade } \\
\text { 5. Assertividade } \\
\text { 6. Auto-controle } \\
\text { 7. Despedida }\end{array}$ & Total $=19$ \\
\hline 2 & $\begin{array}{l}\text { 1. Identificação do entrevistado } \\
\text { 2. Procedimentos antes e depois da entrevista - questões }\end{array}$ & $\begin{array}{r}4 \\
\text { Total }=20 \\
16\end{array}$ \\
\hline 3 & 1. Apresentação & Total $=7$ \\
\hline 4 & $\begin{array}{l}\text { 1. Identificação do atleta } \\
\text { 2. Motivos para a prática desportiva } \\
\text { 3. Início da prática desportiva como atleta de alta competição } \\
\text { 4. Motivação e desempenho desportivo } \\
\text { 5. Motivação e liderança } \\
\text { 6. Motivação e competências de vida }\end{array}$ & Total $=23$ \\
\hline 5 & $\begin{array}{l}\text { 1. Identificação do entrevistado } \\
\text { 2. Roteiro de entrevista } \\
\text { 3. Final da entrevista }\end{array}$ & Total $=26$ \\
\hline 6 & $\begin{array}{l}\text { 1. Apresentação } \\
\text { 2. Características da amostra } \\
\text { 2.1 Dados pessoais } \\
\text { 3. Liderança do treinador e promoção de competências } \\
\text { 3.1. Estilos de liderança } \\
\text { 3.2. Aprendizagens } \\
\text { 3.3. Relação atleta/treinador } \\
\text { 4. Terminus }\end{array}$ & $\begin{array}{l}\text { Total }=37 \\
\text { Th }\end{array}$ \\
\hline
\end{tabular}




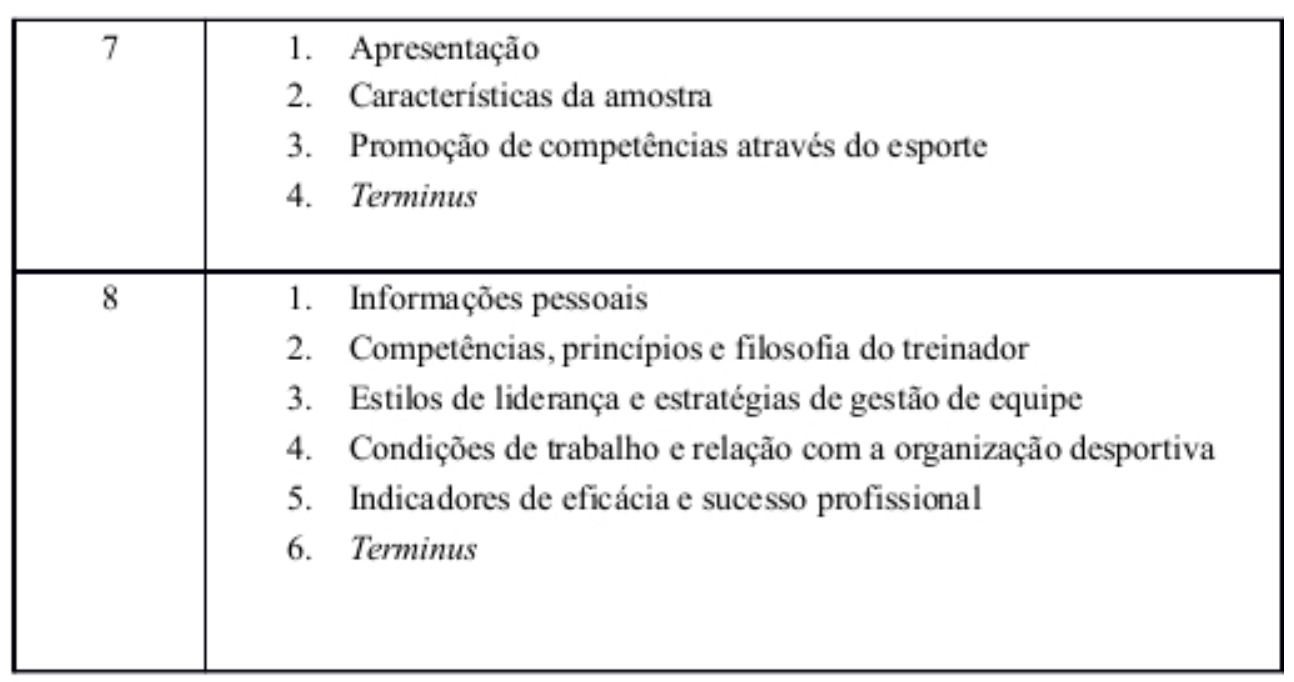

Quadro 2: Entrevistas - blocos temáticos e questões

Conforme mostra o Quadro 2, os blocos temáticos dos diferentes roteiros de entrevista divulgam estruturas diferenciadas. O roteiro de entrevista do T3, por exemplo, apresenta um único bloco com 7 questões e o T8 seis blocos temáticos para um total de 32 questões.

A seguir, damos a conhecer indicadores de competências de vida desenvolvidos em contexto desportivo, partindo de afirmações dos diferentes intervenientes desportivos entrevistados (Quadro 3).

Das questões colocadas e respostas dadas por cada entrevistado, selecionamos aquela(s) que consideramos ser as mais elucidativas do desenvolvimento de competências de vida em contexto desportivo. E1 e E2 representam os agentes desportivos entrevistados pelo respectivo grupo (T1, T2, T4, T5, T7, T8). 
Q19: "Considera que o contexto desportivo será um contexto favorável à aprendizagem da liderança, da responsabilidade, da assertividade, do auto-controle? Se sim, será que nos pode dar alguns exemplos da sua vida profissional?"'(T1)

1. "Sim, considero. Principalmente assiduidade, responsabilidade atitude e profissionalismo" (T1-E1)

2. "Sim, obviamente. Liderança, não havendo ninguém quer internamente, quer externamente que interfira nas minhas decisões. Responsabilidade, saindo quer dos treinos, quer dos jogos, com a consciência tranquila que fiz o melhor para o grupo. Assertividade, sabendo que no futebol, em particular, o certo e o errado é resultante de um bom ou mau resultado desportivo. Auto-controle, sabendo que os atletas quer nos treinos quer nos jogos consigam respeitar todas as minhas decisões"(T 1-E2)

Q20: "A responsabilidade, o auto-controle, a cooperação e a assertividade são competências utilizadas em vários contextos da nossa vida. Considera que o contexto desportivo possa contribuir para o seu desenvolvimento? De que forma? Consegue dar exemplos?" (T2)

1. “ (...) é um esporte coletivo e para se alcançarem objetivos e se atingirem resultados é necessário, é imperativo que exista uma responsabilização individual e fundamentalmente coletiva bem como a cooperação entre os vários elementos constituintes de um grupo e uma capacidade de uma melhor tomada de decisão nos vários momentos, de forma a resolver os problemas que surgem no jogo e na vida"(T2-E1)

2. "O que se vai aprendendo na vida desportiva nos faz crescer como homens e nos prepara também para ultrapassar alguns obstáculos que vamos encontrando ao longo da vida"(T2-E2)

Q19: "O que considera que tem aprendido em contexto desportivo que lhe é útil noutros contextos da sua vida?" (T4)

1. "Gerir o controle de emoções"(T4-E1)

2." Muitas vezes a calma, muitas vezes a luta e não baixar os braços e não desistir porque por pior que as coisas estejam pode sempre haver uma volta a dar e eu acho que a relação com as pessoas é muito importante no esporte"(T4-E2)

Q12: "Considera que há uma chave para o sucesso? Se sim, qual será?" (T5)

1. "Esta é difícil (...) enquanto atleta acho que a chave para o sucesso é a disciplina (...), o cumprimento de horários, muito treino, muito trabalho árduo e muitos sacrifícios" (T5-E1)

2. "Eu acho que a chave do sucesso é o querer, o trabalho, ter uma boa alimentação e muito fator psicológico"(T5-E2)

Q37: "Que aprendizagens considera que a prática desportiva lhe tem proporcionado? Considera que essas aprendizagens são importantes para outros contextos da sua vida?" (T7) 1. "Aprendi a ser mais humilde, a lidar com a derrota, a não desistir nunca mesmo quando parece que não há mais solução, a ser correta ...”(T7-E1)

2. "Claro, é muito importante. A disciplina, a força que temos para lutar pelo que queremos, não desistir quando as coisas correm mal. Temos que ter força para lidar com isso"(T7-E2)

Q29: “Como avalia a sua eficácia enquanto treinador?” (T8)

1."Quando não tenho atletas a abandonar; quando tenho atletas nos escalões mais de formação que evoluem e que reconhecem que evoluíram, quando tenho atletas, que na escola, me dizem que estão bem sucedidos, então eu também acho que contribuo alguma coisa com isso"'(T8-E1)

2. "Eu acho que consigo passar bem (...). Porque é assim, quando os meus alunos (...) Quando eles vão para outros lados muitas vezes telefonam e mandam mensagens a dizer que têm saudades da academia. Quando eu levo os meus alunos a outros lados para provas não me sinto inferiorizado em relação ao trabalho que é desenvolvido por outros clubes"(T8-E2)

Quadro 3: Indicadores de competências de vida (T1, T2, T4, T5, T7, T8)

Pensar a Prática, Goiânia, v. 15, n. 3, p. 551-820, jul./set. 2012 
Os dados do Quadro 3 revelam a liderança, a responsabilidade, a comunicação interpessoal, o desenvolvimento pessoal, a formulação de objetivos e a gestão de emoções como indicadores de competências abordados por estes intervenientes desportivos.

No final do semestre, como forma de aprendizagem formativa, os estudantes receberam um documento onde constava um conjunto de questões promotoras da reflexão sobre o desempenho acadêmico na tarefa concreta de realização deste trabalho de grupo. De um conjunto de 30 questões deixadas aos estudantes no dia 20 de janeiro de 2011 no moddle selecionamos as que se apresentam no Quadro 4.

1. Será que responderam ao solicitado? Incluíram no trabalho as atas das reuniões e as reflexões individuais?

2. Como se apresentam as referências bibliográficas? Qual a norma adoptada? Como se apresenta a referência de um livro, de um artigo de revista? Como se apresenta a referência de um artigo retirado da internet?

3. Será que todos os autores que surgem no corpo do trabalho estão devidamente assinalados nas referências bibliográficas?

4. Que cuidado houve na construção frásica e na elaboração da pontuação? Será que releram o trabalho? Qual o cuidado a ter em termos de linguagem em um trabalho desta ordem?

5. Quais as obras de metodologia de investigação que leram?

6. Como se faz a transcrição de uma entrevista?

7. O que são resultados e como se analisam os resultados, em contexto de investigação?

8. Quando se fala de método, que informação se deve dar sobre os participantes, instrumento, procedimento, dados, discussão?

9. O que é uma reflexão sobre o trabalho desenvolvido?

10. Para a realização de um trabalho acadêmico, ao nível do Ensino Superior, será suficiente a leitura de uma/duas obras/capitulos/artigos?

Quadro 4: Avaliação formativa

Os dados evidenciados nas questões formuladas revelam dificuldades dos estudantes ao nível da metodologia de investigação e da organização de um trabalho acadêmico.

Ao longo do semestre fomos realizando registos das questões que os estudantes iam colocando. Esses registos foram organizados (Quadro 5) e analisados. 
1. Selecionar a tipologia de trabalho a efetuar (revisão da literatura ou ensaio de investigação?)

2. Discutir formas de operacionalizar o trabalho (temos que reunir para discutir o que se vai fazer? não temos nada para discutir ...)

3. Valorizar as componentes do trabalho (construção do roteiro, realização da entrevista, leitura e análise dos dados, realização de atas, reflexão do processo vivido, organização de toda a informação)

4. Assimilar o significado formativo do trabalho (afinal, isto tem lógica!)

5. Escrever de forma rigorosa e clara (temos mesmo que utilizar essas palavras? Era isso que queriamos dizer ...)

6. Gerir o tempo (temos muitos trabalhos para fazer ...; não temos tempo para pensar neste trabalho);

7. Procrastinação (ainda não começamos ...; vamos começar este fim de semana)

8. Compreender o que estava a ser solicitado (o que é isso de roteiro de entrevista? Quais as questões a colocar?)

9. Valorizar a reflexão (tem mesmo que se fazer a reflexão?)

Quadro 5: Conquistas/dificuldades dos estudantes na construção do trabalho

As conquistas/dificuldades dos estudantes evidenciadas ao longo do processo de realização do trabalho revelam lacunas ao nível de competências pessoais transversais (tomada de decisão, gestão do tempo, resolução de problemas) e competências acadêmicas (componentes de um trabalho acadêmico).

\section{Discussão e considerações finais}

A unidade curricular de Psicologia do Esporte (IPL-ESECS, ano letivo 2010/2011) procurou assumir uma formação inicial firme em uma pedagogia participativa. Incentivou a colaboração entre pares, a negociação e a aprendizagem auto-regulada (VIEIRA, 2005; ALARCÃO, 2009; FIGUEIREDO, 1997).

Em uma perspectiva de desenvolvimento de competências, procurou-se a mobilização de conhecimentos e saberes para a resposta a uma situação concreta (DIAS, 2009; PINHEIRO, 2005). Solicitou-se a realização de um trabalho acadêmico em grupo que reclamou a construção de um roteiro de entrevista organizado em blocos temáti$\cos$.

O processo de construção deste roteiro de entrevista revelou-se um desafio para os estudantes. Procurando obter dados sobre as represen- 
tações de atletas e treinadores sobre o papel do contexto desportivo no desenvolvimento de competências de vida:

"a construção da entrevista foi efetuada para ser utilizada numa organização sequencial, onde as questões e os temas a abordar são determinados previamente, mas deixando margem de manobra suficiente ao entrevistador para explorar, o mais detalhadamente possível, aquilo que é referido pelos entrevistados em cada um dos domínios estabelecidos". (GOMES, 2007, p. 105).

A estrutura do roteiro procurou considerar procedimentos prévios (âmbito da realização do trabalho, objetivos do estudo, autorização para a gravação da entrevista, por exemplo), a entrevista propriamente dita e um terminus, aproximando-se de uma estrutura semi-dirigida (SAVOIE-ZAJC, 2003) ou semi-estruturada (GIL, 1991; FLICK, 2005).

As questões incluídas nas entrevistas procuraram abordar as competências de vida atendendo aos dados de Danish $(1993,1995)$ e Cruz, Gomes, \& Dias (1999).

As competências de vida ajudam o indivíduo a ter sucesso no esporte e em outros contextos (família, escola, trabalho, comunidade). Podem e devem ser transpostas de domínio de ação. De acordo com Danish (1993, 1995), o contexto desportivo apresenta-se como um ambiente propício para a aprendizagem e transferência de competências para outros contextos uma vez que promove a mobilização de uma série de competências (ter rendimento sob pressão, resolver problemas, lidar com sucesso e com fracasso, fazer frente a desafios, aceitar valores, atitudes e crenças dos outros, ser flexível, ser paciente, aceitar correr riscos, formular objetivos, saber ganhar e perder, respeitar os outros, ter auto-controle, explorar limites pessoais, competir, ser responsável, fazer auto-avaliações, comunicar, trabalhar em equipe, etc).

Sabendo que as competências físicas e as competências de vida se aprendem através da demonstração, modelagem e prática (DANISH \& HALE, 1981; ORLICK \& MACCAFFREY, 1991), encorajou-se os estudantes a valorizarem esta área da Psicologia do Esporte, refletindo sobre o seu significado para a sua vida profissional futura.

Em síntese, este processo de ensino/aprendizagem procurou promover o desenvolvimento de competências acadêmicas transversais. Recorrendo a uma metodologia ativa, os estudantes foram sendo 
acompanhados no processo de construção do trabalho do grupo revelando-se esta estratégia laboriosa tendo sido necessário incentivar as conquistas realizadas em cada fase da construção do trabalho. O contato com agentes desportivos revelou-se uma experiência satisfatória para os estudantes incentivando a continuação de novas práticas formativas análogas.

\title{
The Sport Psychology in sport technician training
}

\begin{abstract}
The present study aims to share the teaching/learning methodology used in the unit of Sport Psychology from the second year of initial training in the course of Sports and Well-Being (Polytechnic Institute of Leiria - School of Education and Social Sciences) in the academic year of 2010/2011. We have adopted an active approach and encouraged the continuous evaluation focused on classes' participation, individual assessment and the achievement of a working group. From an universe of 82 students, 43 selected continuous assessment and fourteen work groups were done. In this context, we intend to share the data from research working group paper and the formative students' paths in its conception.
\end{abstract}

Keywords: Education. Psychology. Competences.

\section{La Psicología del Deporte adentro del entrenamiento del técnico del deporte}

\section{Resumen}

El actual estudio apunta compartir la metodología de enseñanza/aprendizaje usada en la unidad de psicología del deporte del segundo año de entrenamiento inicial en el curso de Deportes y de Bienestar (Instituto politécnico de Leiria - Escuela de la Educación y de las Ciencias Sociales) en el curso académico de 2010/2011. Hemos adoptado un acercamiento activo y hemos animado la evaluación continua centrada en la participación de las clases, el gravamen individual y el logro de un grupo de trabajo. De un universo de 82 estudiantes, 43 seleccionaron el gravamen continuo y catorce grupos de trabajo fueron hechos. En este contexto, nos preponemos compartir los datos del papel del grupo de trabajo de la investigación y de las trayectorias formativas de los estudiantes en su concepto.

Palabras clave: Educación. Psicología. Competencias.

\section{Referências}

ALARÇÃO, I. Formação e Supervisão de Professores: uma nova abrangência. Sísifo/Revista de Ciências da Educação, n. 8, p. 119$127,2009$.

BEZARA, M. Uma nova didática para o ensino universitário: respondendo ao desafio do espaço europeu de ensino superior. In: Texto da

Pensar a Prática, Goiânia, v. 15, n. 3, p. 551-820, jul./set. 2012 
Sessão Solene Comemorativa do Dia da Universidade, 2006, Porto: Universidade do Porto, 2006.

BULMER, M. When is disguise justified? Alternatives to covert participant observation. Human Sciences Press - Qualitative Sociology, p. 251-264, 1982.

CRUZ, J. F. Manual de Psicologia do Desporto. Braga: SHO-Sistemas Humanos e Organizacionais, 1996.

CRUZ, J., GOMES, R., \& DIAS, C. O ensino de competências de vida através do esporte. Primeiras Jornadas Internacionais sobre toxicodependências: diferentes abordagens, pp. 91-113, 1999. Disponível em http://repositorium.sdum.uminho.pt/handle/1822/9363. Acesso em: 5 jan. 2011.

DANISH, S. J., \& HALE, B. D. Toward an understanding of the practice of sport psychology. Journal of Sport Psychology, 3, p. 90-99, 1981.

DANISH, S. J. A life skills, multi-site intervention program for adolescents. NMHA Prevention Update, 4, p. 8-9, 1993.

. Reflections on the status and future of community psychology. Community Psychologist, 28, p. 16-18, 1995.

. Going for the goal: a life skills program for adolescents. In G. A $\bar{L}$ BEE, \& T. GULLOTTA (Eds.). Primary prevention works, vol. 6. London: Sage Publications, Inc, p. 291-312, 1997.

DIAS, I. (Resp.) Programa da unidade curricular Psicologia do Desporto. Leiria: Escola Superior de Educação e Ciências Sociais, 2010.

DIAS, M. I. Promoção de competências em educação. Leiria: INDEA, 2009.

FIGUEIREDO, A. A formação de treinadores no esporte federado treinador no segundo milênio. II Congresso de gestão do esporte comunicações. Lisboa: APOGESD, p. 113-121, 1997.

FLICK, U. Métodos Qualitativos na Investigação Científica. Lis- 
boa: Monitor-Projetos e Edições, Lda, 2005.

FRASES-THOMAS, J., COTÉ, J., \& DEAKIN, J. Youth sport programs: an avenue to foster positive youth development. Psysical Education and sport pedagogy, vol. 10, n. 1, 2005 p.19-40. Routledge: Taylor and Francis Group. Disponível em http://www.queensu.ca/skhs/ContactUs-2/Faculty-1/Faculty-JeanCote/CotePublications/CotePublications2005/FraserThomasetalPESP2005.pdf. Acesso em: 20 dez. 2009.

GIL, A. Métodos e Técnicas de Pesquisa Social. São Paulo: Editora Atlas, 1991.

GARCIA, R. Para um ensino superior de qualidade. Revista Portuguesa de Ciências do Desporto, vol. 1, n. 1, p. 33-43, 2001.

GOMES, R., RAMALHO, V., \& DIAS, I. Treino de competências de vida em jovens atletas: dados da eficácia de um programa de intervenção. In: C. NOGUEIRA, I. SILVA, L. LIMA, A. T. ALMEIDA, R. CABECINHAS, R. GOMES, C. MACHADO, A. MAIA, A. SAMPAIO, \& M.C. TAVEIRA (Eds.) Atas do VII Simpósio Nacional de Investigação em Psicologia, 20 10, p.1977-1991, Lisboa: Associação Portuguesa de Psicologia. Disponível em http://www.actassnip2010.com. Acesso em: 7 jun. 2010.

GOMES, A. R. Liderança e gestão de equipes desportivas: desenvolvimento de um roteiro de entrevista para treinadores. In: J.F. CRUZ, J.M. SILVÉRIO, A.R. GOMES, \& C. DUARTE (Eds.), Actas da Conferência Internacional de Psicologia do Desporto e Exercício, Braga: Universidade do Minho, p.100-115, 2007.

GOMES, A. R. \& CRUZ, J. Avaliação psicológica de atletas em contextos de formação desportiva: desenvolvimento de um roteiro de entrevista para crianças e jovens. In J.F. CRUZ, J.M. SILVÉRIO, A.R. GOMES, \& C. DUARTE (Eds.), Actas da Conferência Internacional de Psicologia do Desporto e Exercício, Braga: Universidade do Minho, p. 82-99, 2007.

GOULD, D., \& CARSON, S. Life skills development through sport: current status and future directions. International Review of Sport and Exercise Psychology, vol. 1, n. 1, p. 58-78, 2008. 
GOULD, D., CHUNG, Y., SMITH, P., \& WHITE, J. Future directions in coaching life skills: understanding high school coaches' views and needs. Athletic Insight, the online journal of sport psychology, vol., 8, issue 3, p. 28-38, 2006.

INSTITUTO POLITÉCNICO de LEIRIA. Regulamento Geral da Formação Graduada e Pós-graduada no Instituto Politécnico de Leiria e Regimes Aplicáveis a Estudantes em Situações Especiais. Leiria: Rolo \& Filhos II, S.A, 2008.

ORLICK, T., \& McCAFFREY, N. Mental training with children for sport and life. The Sport Psychologist, n. 5, p. 322-334, 1991.

PINHEIRO, A. As competências e as aprendizagens nos contextos acadêmicos e profissionais. Educação \& Comunicação, n. ${ }^{\circ}$ 8, 2008, p. 9-22, 2005.

PROENÇA, J. Questionar a educação (física): da definição de prioridades para a escola e para a flexibilidade dos currículos. Revista Lusófona de Humanidades e Tecnologias, n. ${ }^{\circ}$ 1, p. 132-135, 1999.

SAMUELS, S. E. Transferable life skills learned through sports participation by university athletes committed to their sport. EUA: University of British Columbia, 2002. Disponível em https://circle.ubc.ca/bitstream/handle/2429/17755/ubc_20060300.pdf?sequence=1. Acesso em: 7 mar. 2010.

SAVOIE-ZAJC, L. A Entrevista Semi-dirigida. In: B. GAUTHIER (Ed.), Investigação Social. Da problemática à colheita de dados, p.279-302, Loures: Lusociência, 2003.

VIEIRA, F. Transformar a Pedagogia na Universidade? Currículo sem Fronteiras, vol. 5, n. 1, p. 10-27, 2003.

Recebido em: 04/06/2011

Revisado em: 07/11/2011

Aprovado em: 12/03/2012

Endereço para correspondência

mdias@esecs.ipleiria.pt

Isabel Dias

Instituto Politécnico de Leiria 
DOI 10.5216/rpp.v15i3.14578

Av. Gen. Humberto Delgado, 2410

Leiria, Portugal.

Pensar a Prática, Goiânia, v. 15, n. 3, p. 551-820, jul./set. 2012 